\title{
Principais alterações físico-químicas em óleos e gorduras submetidos ao processo de fritura por imersão: regulamentação e efeitos na saúde
}

\author{
Major physical and chemical changes \\ in oils and fats used for deep frying: \\ Regulation and effects on health
}

Poliana Cristina Mendonça FREIRE ${ }^{1}$

Jorge MANCINI-FILHO²

Tânia Aparecida Pinto de Castro FERREIRA ${ }^{3}$

RE S U M O

Alimentos fritos são muito consumidos no Brasil e no mundo. Sabe-se que a fritura é um processo complexo e oferece riscos à saúde humana. Um dos objetivos desta revisão foi apresentar as principais alterações físicas (escurecimento, viscosidade e formação de espuma) e químicas (hidrólise e auto-oxidação) que ocorrem nos óleos e/ou gorduras durante o processo de fritura. Outro objetivo foi abordar os principais fatores envolvidos na degradação do óleo e/ou da gordura de fritura (temperatura e tempo de fritura; relação superfície/volume; tipo de aquecimento; tipo de óleo; adição de óleo novo; natureza e quantidade do alimento frito; presença de contaminantes metálicos e equipamento utilizado, além da presença de antioxidantes). Foram também apresentados alguns métodos de controle de qualidade de óleo ou de gordura de fritura existentes (quantificação de compostos polares totais, acidez, índice de peróxidos, valor de p-anisidina e métodos rápidos de quantificação). Por fim, foram relacionadas as regulamentações vigentes sobre o processo de fritura, os efeitos dos compostos degradados sobre a saúde humana e algumas recomendações para a melhoria da qualidade do óleo ou da gordura de fritura formuladas pelo Informe Técnico nº 11 da Agência Nacional de Vigilância Sanitária.

Termos de indexação: Degradação lipídica. Fritura. Regulamentação. Saúde.

A B S T R A C T

Fried foods are widely consumed in Brazil and in the world. Frying is a complex process with human health risks. One of the objectives of this review was to present the main physical changes (darkening, viscosity and

\footnotetext{
1 Instituto Federal de Educação, Ciência e Tecnologia de Goiás. Goiânia, GO, Brasil.

2 Universidade de São Paulo, Faculdade de Ciências Farmacêuticas. São Paulo, SP, Brasil.

${ }^{3}$ Universidade Federal de Goiás, Faculdade de Nutrição. R. 227, Quadra 68, s/n., Setor Leste Universitário, 74605-080, Goiânia,

GO, Brasil. Correspondência para/Correspondence to: TAPC FERREIRA. E-mail: <taniaferreira@fanut.ufg.br>.
} 
foam formation) and chemical changes (hydrolysis and autoxidation) that occur in oils and/or fats during the frying process. Another objective was to investigate the main factors associated with oil and/or fat degradation, namely frying temperature and time; surface/volume ratio; type of heating; addition of new oil; type and quantity of the food being fried; presence of metal contaminants; equipment used; and presence of antioxidants. Some existing frying oil or fat quality control methods (total polar compound analysis, acidity, peroxide index, p-anisidine value and rapid quantitative methods) were also presented. The review closes with the regulations concerning the frying process, effects of degraded compounds on human health, and recommendations for improving frying oil or fat quality listed in Technical Report $n^{\circ} 11$ of the National Sanitary Surveillance Agency.

Indexing terms: Lipid degradation. Frying. Regulation. Health.

\section{N T R O D U Ç Ã O}

A fritura é uma alternativa eficiente e de baixo custo para preparação rápida de alimentos. Constitui um processo complexo, no qual o alimento é submerso em óleo ou gordura quente que, ao agir como meio de transferência de calor, confere ao produto características agradáveis de cor, sabor e textura. Assim, o óleo ou a gordura de fritura além de se incorporar ao alimento, modificando suas propriedades nutricionais e sensoriais, é um meio reutilizável de transferência de calor, mais eficiente que o forneamento e mais rápido que a cocção em água ${ }^{1,2}$.

Alimentos fritos são muito consumidos no Brasil, sendo largamente comercializados em bares, lanchonetes, restaurantes, indústrias de salgadinhos (snacks, chips), cadeias de alimentação rápida (fast food), pastelarias, bem como por ambulantes em feiras livres, praças e locais públicos ${ }^{3}$. Esses alimentos alcançaram grande destaque com a urbanização do país, que tem valorizado cada vez mais a praticidade, a redução do tempo para o preparo dos alimentos e a facilidade de consumo ${ }^{4}$.

Essa tendência do crescimento da alimentação fora do domićlio, incluindo os alimentos fritos, é corroborada pelos dados da Pesquisa de Orçamento Familiar (POF) de 2002-2003 e mais recentemente pelos dados da pesquisa de 2008-2009. A pesquisa mostrou um aumento significativo no percentual da despesa média com alimentação fora do lar: de 24,1 para 31,1\%. Entre as grandes Regiões metropolitanas, ocorreu maior gasto entre as famílias da Região Sudeste $(37,2 \%)$, seguida pelas Regiões Centro-Oeste
$(30,1 \%)$ e Sul $(27,7 \%)$, enquanto os menores percentuais de despesa estão nas Regiões Norte $(21,4 \%)$ e Nordeste $(23,5 \%)^{5,6}$.

Muitas propriedades dos alimentos fritos são alteradas, como qualidade sensorial e nutricional e toxicidade ${ }^{7,8}$, podendo chegar a níveis em que o produto se torna impróprio para o consumo e sem a qualidade desejada. A determinação do ponto de descarte dos óleos de fritura é importante, uma vez que implica maior custo quando o óleo é descartado muito cedo e perda da qualidade do alimento frito quando descartado tardiamente, o que o torna prejudicial para a saúde da população9 .

O objetivo desta revisão foi destacar as alterações que ocorrem durante o processo de fritura, como as modificações físicas e químicas e os fatores envolvidos na degradação do óleo e/ou gordura de fritura, e mencionar alguns dos métodos de controle de qualidade existentes, relacionando as regulamentações vigentes, os efeitos dos compostos sobre a saúde e, finalmente, apresentar algumas recomendações para a melhoria da qualidade desse óleo e/ou gordura de fritura.

\section{M É T O D O S}

Este trabalho é uma pesquisa do tipo bibliográfico e de cunho exploratório, que visa revisar as informações disponíveis na literatura sobre o processo de fritura a partir do ano 2000 até 2012, além de consultar artigos importantes sobre $o$ assunto publicados anteriormente ao ano de 2000. 
Para a realização do estudo, foram consultados artigos científicos e periódicos publicados em bases bibliográficas disponíveis através de websites, como o http://www.bireme.br, que busca dados no Lilacs e MedLine, (http://www. periodicos.capes.gov.br), que disponibiliza dados do MedLine, FSTA, CAB Abstracts, AGRIS, Web of Science, e ainda o SciELO (http://www.scielo. br). Foram consultados também artigos contidos em anais de congressos. As palavras-chave pesquisadas foram: fritura, degradação lipídica, regulamentação e saúde. Também foram utilizados descritores do assunto presentes no site de busca: (www.bireme.br), que permitiu um melhor acesso de material para a presente pesquisa.

Foram selecionados os artigos que apresentaram a descrição do método de avaliação da qualidade do óleo, os que utilizaram métodos de determinação de compostos formados na fritura de forma rápida e os que compararam testes rápidos com testes laboratoriais, além daqueles que analisaram o efeito da fritura sobre a saúde humana.

\section{ALTERAÇÕES NOS ÓLEOS E GORDURAS DURANTE O PROCESSO DE FRITURA DE IMERSÃO}

Existem dois tipos de fritura de imersão: a contínua e a descontínua. Na primeira, o alimento é frito em uma só etapa em que o óleo é continuamente aquecido, sendo normalmente utilizada pelo mercado industrial de snacks extrusados, massas fritas, pré-fritura e fritura de batatas. Na fritura descontínua, o óleo ou gordura são aquecidos repetidas vezes, ou seja, são aquecidos para uma refeição, são resfriados e reaquecidos posteriormente para o preparo da refeição seguinte. Acontece principalmente no processo caseiro e no mercado institucional: redes de fast food, restaurantes, lanchonetes, cantinas escolares e pastelarias ${ }^{1}$.

No processo de fritura contínua, acontece a reação de hidrólise com a formação de ácidos graxos livres que alteram as características sensoriais do produto e diminuem o ponto de fumaça do óleo/gordura de fritura. No processo de fritura descontínua, ocorrem reações de oxidação, hidrólise e polimerização, produzindo moléculas complexas e compostos voláteis, como a acroleína (responsável por um aroma desagradável no ambiente). Nesse estágio, há o aumento do ponto de fumaça ${ }^{10}$.

Além do ponto de fumaça, ocorrem outras mudanças físicas, como formação de espuma, aumento da viscosidade e escurecimento. A formação de espuma e o aumento da viscosidade estão relacionados com a presença de compostos resultantes da oxidação do óleo ou da gordura, e o escurecimento é atribuído à presença de compostos não polares provenientes dos alimentos que são solubilizados no meio de fritura ${ }^{11}$.

As mudanças químicas que ocorrem podem ser resumidas em dois tipos de reações: hidrólise e auto-oxidação ${ }^{12}$. As reações hidrolíticas são catalisadas pela ação do calor e umidade, com a formação de ácidos graxos livres, monoacilglicerol e diacilglicerol. A auto-oxidação lipídica está associada à reação do oxigênio com ácidos graxos insaturados e acontece em três etapas: iniciação, propagação e término ${ }^{13}$. Na iniciação, são formados radicais livres a partir da retirada de um hidrogênio do carbono da molécula do ácido graxo, em condições favorecidas por luz e calor. A propagação é a etapa em que os radicais livres são prontamente susceptíveis ao ataque atmosférico, sendo convertidos em outros radicais, formando peróxidos e hidroperóxidos, dienos conjugados, hidróxidos e cetonas, que são os produtos primários da oxidação ${ }^{11,13}$ e que podem se decompor em pequenos fragmentos ou permanecer na molécula do triacilglicerol dimérico e polimérico. Assim, a última etapa do processo de oxidação é o término, onde dois radicais combinam-se, formando produtos estáveis (produtos secundários de oxidação) obtidos por cisão e rearranjo dos peróxidos (epóxidos, compostos voláteis e não voláteis $)^{14}$. 
À medida que se aumenta o uso do óleo na fritura, as reações de oxidação se intensificam e há produção de moléculas complexas e compostos voláteis que liberam aroma desagradável. Nesse ponto, a fritura produz muita fumaça e, consequentemente, o alimento tem sua vida de prateleira diminuída, apresentando aroma, sabor e aparência desagradáveis, podendo apresentar excesso de óleo absorvido e o centro do alimento não completamente cozido ${ }^{10}$.

\section{PRINCIPAIS FATORES ENVOLVIDOS NA DEGRADAÇÃO DO ÓLEO E/OU GORDURA DURANTE O PROCESSO DE FRITURA}

Os principais fatores envolvidos na degradação do óleo durante o processo de fritura são: temperatura e tempo de fritura; relação superfície/volume do óleo; tipo de aquecimento; tipo de óleo; adição de óleo novo; natureza e quantidade do alimento frito; presença de contaminantes metálicos e equipamento utilizado no processo de fritura, além da presença de antioxidantes nos óleos ${ }^{9,15}$.

A temperatura de fritura tem sido vista como um dos principais aspectos da qualidade do alimento e do óleo de fritura. Durante os processos que utilizam aquecimento, quando a temperatura do óleo e da gordura fica acima de $180^{\circ} \mathrm{C}$, ocorre a emissão de fumaça e o início dos processos oxidativos $^{16,17}$.

O tempo de fritura é diretamente relacionado à degradação do óleo e da gordura ${ }^{18}$. Assim, o binômio tempo-temperatura de aquecimento são fatores preponderantes no processo de fritura, já que influenciam consideravelmente o nível de alteração do óleo e da gordura. Além disso, são variáveis dependentes entre si, pois o tempo de fritura necessário para o desenvolvimento da cor e da textura adequadas no alimento depende da temperatura utilizada. Um tempo de aquecimento longo se traduz em aumento do nível de alteração com formação de diferentes compostos, seguido por uma estabilidade desses elementos. Mesmo um período curto de aquecimento já é prejudicial ao óleo e à gordura ${ }^{9,19}$.

É válido ressaltar que a duração do processo de fritura está na dependência não somente da temperatura do óleo ou da gordura e do alimento, mas também da quantidade de alimento, seu tamanho, forma e conteúdo inicial do óleo'.

A relação Superfície/Volume $(S / V)$, em alguns estudos, tem sido empregada como fator de alteração do óleo, já que a taxa de oxidação depende da área superficial do óleo exposto ao contato com o oxigênio do ar. Em estudo sobre a influência da relação $S N$ na fritura de batata palito no óleo de soja, o aumento da relação SN e o prolongamento do tempo de fritura influenciaram diretamente na alteração do óleo. As alterações físicas e químicas no óleo foram maiores na relação $S N$ de $0,6 \mathrm{~cm}^{-1}$. Dentre os tempos de fritura estudados, os produtos fritos em óleo com até 9,5 horas de tempo de utilização foram os mais recomendados, pois acima desse tempo de fritura, observou-se aumento do nível de alteração, principalmente na análise de Compostos Polares Totais (CPT), atingindo valores de $25,2 \%$ e $26,57 \%$ nas relações $S N$ de 0,4 e $0,6 \mathrm{~cm}^{-1}$, respectivamente ${ }^{20}$ (considerando-se o valor máximo de $25,0 \%$ ). Em outro trabalho realizado com amostras de óleos de soja, após 0,$25 ; 1,25 ; 2,25$; 3,$25 ; 4,25 ; 5,25 ; 6,25$ e 7,25 horas de fritura, o aumento da relação $S / V$ apresentou efeito significativo na alteração do óleo, uma vez que as modificações nos CPT e nos índices de peróxidos e de refração fo-ram mais evidentes na relação $S N$ de $1,0 \mathrm{~cm}^{-1} 9$. Assim, a decomposição de óleos e gorduras pode ser diminuída se o processo de fritura for realizado com pequena quantidade de óleo ou de gordura, em recipientes altos e estreitos, diminuindo-se, portanto, o contato desse óleo ou gordura com o oxigênio ${ }^{16}$.

Quanto ao tipo de fritura, McSavage \& Trevisan ${ }^{21}$ distinguem as frituras como rápidas (refogadas), prolongadas por imersão e frituras repetidas com modificações de temperatura entre uma fritura e outra. Entende-se que essas duas últimas classificações estejam incluídas na fritura por 
imersão, que pode ser contínua (prolongada) e descontínua (repetida) - terminologia utilizada pela maioria dos autores para a fritura de imersão. Alguns estudos evidenciam que as frituras descontínuas apresentam maior prejuízo à qualidade do óleo/gordura de fritura ${ }^{22,23}$, enquanto na fritura contínua, o vapor resultante do processo retarda a oxidação ao recobrir a superfície do óleo ou gordura, impedindo o contato com o oxigênio atmosférico ${ }^{24}$.

Também a configuração esterioquímica da molécula do ácido graxo é importante no nível de degradação de óleo ou gordura. Essas informações foram confirmadas pelo estudo de Damy \& Jorge ${ }^{25}$, que verificaram as alterações físicas e químicas do óleo de soja e de gordura vegetal hidrogenada durante o processo de fritura descontínua de batata ao coletarem amostras de óleo após 0,$5 ; 3,5 ; 5,5$ e 7,5 horas de fritura. Os autores observaram que o óleo de soja refinado apresentou maior alteração e maior tendência à polimerização em relação à gordura vegetal hidrogenada, independentemente das temperaturas e dos tempos de fritura. O número, a posição e a geometria das duplas ligações na molécula de ácido graxo afetam a taxa de oxidação dos diferentes tipos de óleo ${ }^{26}$. Assim, por exemplo, os isômeros cis são mais suscetíveis à oxidação do que os isômeros trans ${ }^{27}$. Dessa forma, a gordura vegetal hidrogenada sofre menos oxidação do que o óleo vegetal.

Em relação à adição de óleo novo, observa-se que quanto maior a velocidade de adição de óleo novo àquele em uso, para compensar o óleo absorvido pelo produto frito, melhor sua qualidade momentânea ${ }^{20,25}$. A incorporação frequente de óleo novo (15\% a $25 \%$ ) ao óleo de fritura diminui a formação de CPT, diglicerídios e ácidos graxos livres e pode aumentar o tempo de sua utilização ${ }^{28}$, entretanto a adição de óleo à gordura vegetal hidrogenada provoca uma maior degradação ${ }^{29}$. Dessa forma, recomenda-se evitar o acréscimo de óleo novo à gordura já em uso.

A natureza do alimento frito afeta a composição do óleo utilizado no processo. Quando os alimentos são empanados ou de origem animal (frango, peixe), partículas da superfície podem se desprender para o óleo e serem queimadas, intensificando o seu escurecimento e conferindo sabores e aromas desagradáveis, além de acelerar a degradação do óleo. A fritura de alimentos que contêm ovo na sua preparação pode contribuir para a rápida formação de espuma, pela solubilização da lecitina ${ }^{3}$. Assim, a fritura é bastante apropriada para alimentos de origem vegetal ricos em amido, uma vez que eles, quando imersos no óleo aquecido, tendem a formar uma crosta impermeável que retém em seu interior vapor de água, evitando a absorção de lipídeos ${ }^{20}$.

A presença de ácidos graxos livres pode incorporar metais catalíticos presentes no equipamento e recipientes de estocagem, provocando o aumento da taxa de oxidação ${ }^{30}$. O ferro e o estanho são catalisadores particularmente eficazes do processo de oxidação, enquanto o cobre tem pouco impacto ${ }^{14}$. Assim, é importante verificar o estado de conservação dos equipamentos (riscados, amassados), que podem liberar metais para o óleo ou para a gordura de fritura, bem como a não utilização de utensílios que possam favorecer a liberação de metais. A partir do exposto, o melhor material para se evitar a oxidação por metais catalíticos é o cobre.

Por fim, a presença de antioxidantes no óleo atua bloqueando a formação de radicais livres, mesmo em pequenas quantidades ${ }^{13}$. Entre os antioxidantes, os tocoferóis são encontrados naturalmente na maioria dos óleos vegetais. A legislação brasileira permite a adição de até $300 \mathrm{mg} / \mathrm{kg}$ de tocoferol em óleos e gorduras ${ }^{31}$. Sua ação antioxidante é devida à capacidade de doação de hidrogênios fenólicos aos radicais livres lipídicos, interrompendo a etapa de propagação (fase intermediária da oxidação) ${ }^{13}$.

Muitas redes de fast food estão utilizando gordura vegetal para fritura, um produto que apresenta como função antioxidante Terc-butilhidroquinona (TBHQ), alfa-tocoferol e ácido cítrico ${ }^{13}$. 


\section{ANTIOXIDANTES UTILIZADOS EM ÓLEOS OU GORDURAS DE FRITURA}

Alguns alimentos, como gorduras e óleos, quando aquecidos sofrem oxidação térmica e produzem compostos como peróxidos, que devem se transformar em aldeídos, cetonas, epóxidos, dímeros e polímeros, prejudicando a qualidade dos alimentos ${ }^{32}$.

Com a finalidade de inibir ou retardar a oxidação lipídica, são empregados compostos químicos conhecidos como antioxidantes. Butil-hidroxi-anisol (BHA), Butil-hidroxi-tolueno (BHT), Propil Galato (PG) e TBHQ são os antioxidantes sintéticos mais utilizados na indústria de alimentos ${ }^{33}$.

A estrutura fenólica desses compostos permite a doação de um próton a um radical livre, regenerando, assim, a molécula do acilglicerol e interrompendo o mecanismo de oxidação por radicais livres. Dessa maneira, os derivados fenólicos transformam-se em radicais livres. Entretanto, esses radicais podem se estabilizar sem promover ou propagar reações de oxidação ${ }^{34}$.

Em óleos comestíveis, a escolha de um antioxidante deve ser direcionada para a preservação de ácidos graxos insaturados e para a redução da degradação térmica, que acontece geralmente entre 150 e $220^{\circ} \mathrm{C}^{35}$.

Terc-butilhidroquinona é um pó cristalino branco e brilhoso, moderadamente solúvel em óleos e gorduras e que não se complexa com íons de cobre e ferro, como o galato. É considerado, em geral, mais eficaz em óleos vegetais que $\mathrm{BHA}$ ou BHT; em relação à gordura animal, é tão efetivo quanto o BHA e mais efetivo que o BHT ou o PG ${ }^{36}$. O TBHQ é considerado também o melhor antioxidante para óleos de fritura, pois resiste ao calor e proporciona uma excelente estabilidade para os produtos acabados. Ácido cítrico e TBHQ apresentam excelente sinergia em óleos vegetais ${ }^{33}$.

\section{MÉTODOS DE CONTROLE DE QUALIDADE DO ÓLEO/GORDURA DE FRITURA}

Devido à complexidade do processo de fritura, não há um único método capaz de avaliar com precisão a deterioração dos óleos ${ }^{9}$. Dos inúmeros métodos e equipamentos que têm sido utilizados para analisar a qualidade dos óleos, alguns são caros e longos até se obter o resultado. Entretanto, existem índices analíticos rápidos, simples e precisos, que podem ser de grande interesse para conhecer a evolução dos óleos de fritura em aplicações mais exequíveis ${ }^{25,37}$.

Existem métodos analíticos que quantificam de forma direta os compostos formados durante a oxidação, entre os quais se destaca a determinação de Compostos Polares Totais $(\mathrm{CPT})^{38}$, além de métodos rápidos e reprodutíveis, tais como: determinação de ácidos graxos livres por meio do índice de acidez, índice de peróxidos, índice de iodo e testes colorimétricos ${ }^{9,28}$.

A determinação de CPT é um tipo de análise padrão amplamente reconhecido e confiável no monitoramento do grau de degradação de óleos e gorduras utilizados em fritura. Esse tipo de análise tem sido estabelecido por alguns países como norma de qualidade, tais como Alemanha, Bélgica, Holanda, Estados Unidos, Espanha, Suíça, França, Japão e Chile, em que é estabelecido um teor máximo de $25 \%$ de CPT.

A cromatografia a gás é a técnica oficial, internacional, como o método descrito pelos órgãos oficiais de determinação dos CPT. Ela utiliza como ferramenta a cromatografia em coluna, que se baseia na separação de duas frações: a primeira contendo a parte do óleo que não sofreu alterações físicas e químicas, os triacilgliceróis (porção apolar), e a segunda, em que se concentram os produtos de degradação do óleo, constituída de triacilgliceróis oxidados, polímeros, dímeros, diglicerídios e ácidos graxos livres (porção polar) ${ }^{39,40}$. A diferença de polaridade entre ambos os grupos de compostos constitui a base dessa separação $0^{41}$. Dessa forma, os CPT são quantificados pela dife- 
rença entre a massa de amostra adicionada à coluna e a massa da fração não polar. O tempo médio requerido para cada quantificação é de três horas e meia, sem contar com as oito horas, aproximadamente, destinadas ao preparo do material antes de proceder com as análises ${ }^{42,43}$. Tal técnica exige tempo e muito trabalho, sendo um empecilho para sua utilização em análises de rotina de controle de qualidade ${ }^{25,42}$.

Por possuir mecanismo de separação completamente distinto, economia de solventes e eliminação de etapas de extração, a Eletroforese Capilar (EC) oferece uma boa alternativa na análise de ácidos graxos. Além de apresentar curto tempo de análise, a preparação da amostra é relativamente simples, não sendo necessárias etapas de derivatização (etapa de formação de adutos ou derivativos que apresentem alta absortividade, como fenacil-ésteres, naftacil-ésteres e 2-nitrofenilidrazidas), uma vez que a detecção indireta, seja no caso de radiação Ultravioleta (UV) ou fluorescência, pode ser empregada ${ }^{44}$.

Devido ao seu bom desempenho na análise iônica, a detecção condutométrica em EC tem apresentado larga aceitação, principalmente após a comercialização de equipamentos munidos desse tipo de detector ${ }^{44,45}$.

A Ressonância Magnética Nuclear (RMN) apresenta três grandes vantagens quando comparado à Cromatografia Gasosa (CG). Em primeiro lugar, nenhuma calibração com padrões é necessária antes da análise, é mais rápido, apresenta maior precisão e a duração da análise é mais curta que a CG (cerca de 45 minutos). A técnica de RMN pode ser facilmente aplicada em óleos comestíveis com elevado teor de esterol (por exemplo, óleo de gergelim ou óleo de milho), assim como em óleos deteriorados ${ }^{46}$. No entanto, a metodologia de RMN é incapaz de separar e quantificar os esteróis individuais ${ }^{47}$.

Essa mesma determinação pode ser realizada por métodos mais rápidos pelos equipamentos Fri-Check, Testo 265 e mais recente o Testo 270 e pelos testes colorimétricos, Oil Test e Oxifrit-test.
O Fri-Check é um sistema rápido caracterizado pela simultaneidade de três medidas físicas: viscosidade, densidade e tensão superficial. Os resultados são gerados após cerca de cinco minutos e são expressos em unidades de Fri-Check $(\mathrm{U})$ e porcentagem de compostos poliméricos e equivalente polar. Esse equipamento não requer calibração, mas é pouco utilizado em estudos nacionais $^{42}$.

O Testo 265 e Testo 270 (nova versão do equipamento, com adicionais de maleta e óleo de calibração) são instrumentos que medem diretamente no óleo de fritura o teor de CP, com uma sensibilidade de $0,5 \%$. Apresenta um sensor que pode ser imerso diretamente no óleo quente de 40 a $210^{\circ} \mathrm{C}$ e, após 25 a 30 segundos, o instrumento indica por meio de uma lâmpada led $e$ indicação sonora o estado de qualidade do óleo utilizado $^{41}$. O equipamento baseia-se na constante dielétrica, em que a alteração dielétrica está diretamente relacionada à degradação do óleo ${ }^{27}$.

Já o Oil Test é um teste colorimétrico rápido, em forma de um kit para monitorar a qualidade de óleos ou gorduras de fritura em restaurantes, pastelarias e bancas de feiras. Seu princípio se baseia na avaliação das alterações da acidez e na formação de peróxidos, de modo conjunto. O kit consta de três reativos. Em um tubo, antes da adição do óleo quente, são misturados os reativos 1 e 2 . Depois, é adicionado o reativo 3 e repete-se a agitação. Após três minutos de repouso, a cor obtida é comparada com a escala de cores que aponta o nível de alteração da amostra de óleo, indicando se o óleo deve ou não ser descartado: azul=bom; azul-verde=regular; verde=trocar e verde-oliva=péssimo ${ }^{48}$.

Esse teste já foi utilizado em vários estudos brasileiros. Tavares et al. ${ }^{49}$, em um estudo realizado na Baixada Santista (São Paulo) para avaliar a qualidade de óleos e gorduras utilizados para fritura no comércio da Região Metropolitana, coletaram amostras antes da fritura e depois da fritura em uma única vez e utilizaram o kit. Concluíram que esse teste serve como indicativo de qualidade do óleo e/ou gordura no momento da fritura, é de 
fácil execução e pode ser aplicado por pessoal não especializado.

Outro estudo, por Lopes \& Jorge ${ }^{50}$, com 58 amostras, comparou os resultados obtidos com o kit (oil test) com outros três tipos de testes rápidos utilizados na avaliação da qualidade de óleos e gorduras de fritura: ensaio de Perevalov, monitor de gordura 3M e ensaio de solubilidade em acetona-metanol. Determinaram-se pelos quatro testes compostos polares totais e ácidos graxos livres. O conjunto de reagentes de Oil Test e o monitor de gordura 3M foram adquiridos comercialmente e os outros dois foram realizados em laboratório. No procedimento do ensaio Perevalov, uma amostra foi misturada a $1,5 \mathrm{~mL}$ de óleo/gordura em 3,5mL de uma mistura a $2 \%$ de $\mathrm{NaOH}$ em álcool benzílico e n-propanol (1:3). Em seguida, adicionou-se $0,11 \mathrm{~mL}$ de solução $(0,1 \%$ de azul de bromotimol em dioxano). Após agitação da mistura, observou-se a coloração nos primeiros dois minutos.

A variação da cor está diretamente relacionada ao estado de oxidação do óleo ou gordura - determinada pelo teor de compostos polares totais -, o que permite ter uma impressão rápida do nível de alteração da amostra. Contudo, é considerado por alguns autores como uma prova de campo limitada e subjetiva. Limitada porque testes colorimétricos sofrem interferência da cor, principalmente quando produtos pigmentados são fritos no óleo ou na gordura, ocorrendo a solubilização de pigmentos dos alimentos para o óleo durante o processo de fritura. Subjetiva por-que a avaliação da cor padrão de alteração pode mudar entre um observador e outro ${ }^{41}$.

O monitor de gordura 3M corresponde a uma fita de papel com quatro faixas azuis numeradas que mudam da cor azul para o amarelo à medida que a concentração de ácidos graxos livres aumenta no meio de fritura. Mergulha-se a fita de papel não tóxico na gordura à temperatura da fritura, até que todas as quatro faixas azuis estejam submersas. $\mathrm{O}$ ensaio de solubilidade em acetona-metanol é um ensaio simples, baseado na baixa solubilidade dos compostos de poli- merização na mistura acetona-metanol (90:10) à baixa temperatura. Consiste em pesar $1 \mathrm{~g}$ de amostra e dissolvê-la em $20 \mathrm{~mL}$ de solução acetona-metanol, agitar e deixar por 12 horas em baixa temperatura $\left(4^{\circ} \mathrm{C}\right.$ a $\left.6^{\circ} \mathrm{C}\right) . \mathrm{O}$ aparecimento de um precipitado amarelo corresponde a compostos de polimerização e indica a necessidade de descarte do óleo ${ }^{50}$.

Das 58 amostras analisadas ${ }^{50}$, foram encontrados 20,7 e 15,5\% com teores de CPT e ácidos graxos livres, respectivamente, superiores aos limites estabelecidos em legislações internacionais para óleos e gorduras de fritura. Já os testes rápidos apresentaram resultados corretos em $67,2 \%$ para o ensaio de Perevalov; $87,9 \%$ quando utilizado o kit Oil Test, 75,9\% para o monitor de gordura $3 \mathrm{M}$ e $62,1 \%$ para o ensaio de solubilidade quando comparados ao limite estabelecido para compostos polares totais. O Oil Test foi o que apresentou melhor coeficiente de correlação com o teor de compostos totais $(0,86)$ e menor ocorrência de resultados falsos $(12,1 \%)$ quando comparado aos outros testes ${ }^{50}$.

Bertanha et al. ${ }^{41}$ testaram três métodos: kit oil test (já descrito anteriormente), Oxifrit-test e o teste com Testo 265 comparativamente ao método oficial de determinação dos CPT proposto por Waltking \& Wessels ${ }^{51}$ com pequena modificação (uso de hexano: etér etílico 90:10 em vez de 87:13) para produzir uma melhor separação da fração não polar ${ }^{29,30}$. Foram analisadas 20 amostras de óleos e gorduras de fritura coletadas pontualmente (uma única vez) nos estabelecimentos do ramo de produção de alimentos: restaurantes, lanchonetes e pastelarias. O coeficiente de correlação estimado para avaliar o grau de concordância entre as determinações analíticas para os dois testes colorimétricos foi de 0,929, com 95\% de Intervalo de Confiança (IC) e para os testes Testo 265 e CPT foi de 0,83, com 95\% de IC, apresentando alta correlação com os valores determinados pela metodologia oficial.

De acordo com os resultados acima, os autores concluíram que os testes rápidos são ferramentas valiosas e eficazes no monitoramento 
de óleos e gorduras, e que o Testo 265 torna-se uma boa alternativa para ser utilizado em órgãos de inspeção e fiscalização de serviços de alimentação coletiva, já que os resultados apresentaram alta correlação com os valores determinados pela metodologia oficial e são métodos que permitem obter conclusões rápidas em relação ao momento do necessário descarte do óleo ${ }^{41}$.

Quanto aos métodos físicos e químicos para se determinar a degradação de óleos, Mendonça et al. ${ }^{22}$ avaliaram as alterações físicas e químicas de óleos vegetais utilizados em processo de fritura descontínua em Unidades Produtoras de Refeições (UPR) do Distrito Federal. As amostras foram coletadas a cada dois dias até o descarte do óleo. Realizaram-se 33 análises de acidez titulável, de índice de iodo e de índice de peróxidos. Os autores concluíram que a natureza muito diversificada do alimento frito e o acréscimo de óleo novo ao usado são fatores cruciais para a aceleração da degradação dos óleos, observados pelos índices de acidez e de peróxidos, e que a adição do óleo novo ao usado não permite que o índice de iodo seja utilizado como parâmetro para a escolha do momento de descarte do óleo.

A determinação da acidez pode fornecer um dado importante na avaliação do estado de conservação do óleo. Um processo de decomposição, seja por hidrólise, oxidação ou fermentação, altera quase sempre a concentração dos íons de hidrogênio. A decomposição dos triacilgliceróis é acelerada por aquecimento e pela luz, sendo a rancidez quase sempre acompanhada pela formação de ácidos graxos livres, frequentemente expressos em termos de acidez em grama do componente ácido principal, geralmente o ácido oleico ${ }^{52}$.

Jorge \& Lunardi53 avaliaram as alterações nos óleos de girassol, milho e soja utilizados em frituras descontínuas de batatas, à temperatura de $175^{\circ} \mathrm{C}$, a partir de amostras coletadas em diferentes intervalos de tempos: ao final da primeira e a cada cinco frituras, ou seja, após a $1^{\mathrm{a}}, 5^{\mathrm{a}}, 10^{\mathrm{a}}$ e $15^{a}$ frituras, por meio de métodos analíticos: índice de acidez, índice de peróxidos, período de indução (expresso em horas, obtido a partir da condutividade elétrica dos produtos voláteis da degradação por meio do equipamento Rancimat, marca Metrhom, modelo 743) e determinação de CPT. Das determinações físicas e químicas, esses autores verificaram que os mais adequadas para monitorar o processo de fritura descontínua foram os CPT e os ácidos graxos livres para o óleo de girassol e índice de peróxidos para óleo de milho e de soja.

Jorge \& Janieri ${ }^{54}$ acompanharam o estado de degradação de óleo de soja utilizado em fritura descontínua em um restaurante universitário, e analisaram se o óleo quando descartado ainda estava em condições de uso. As amostras de óleo foram coletadas em duas fritadeiras antes da fritura e após 2,$5 ; 5,0 ; 7,5 ; 10 ; 12,5 ; 15$ horas de fritura. Foram determinados o índice de acidez, o índice de peróxidos, o índice de refração, o índice de iodo e o teor de CPT. Os autores verificaram que o mais adequado para monitorar o processo de fritura descontínua foi CPT para ambas as fritadeiras.

No processo de oxidação, o índice de peróxidos atinge um valor máximo e, em seguida, declina. Esse pico é alcançado após cerca de 20 horas de utilização do óleo em frituras. A temperatura de fritura ocasiona a formação de hidroperóxidos que se decompõem rapidamente dando origem a produtos secundários de oxidação ${ }^{9}$ que podem ser determinados pelo Valor de Anisidina (VA), que estima o nível de aldeído, principalmente 2-alquenal.

Damy \& Jorge ${ }^{25}$ objetivaram em seu estudo determinar as alterações físicas e químicas do óleo de soja e da gordura vegetal hidrogenada durante o processo de fritura descontínua de batata, sendo coletadas amostras de óleo após 0,5; 3,5; 5,5 e 7,5 horas de fritura e realizadas as seguintes determinações analíticas: índice de acidez, CPT, índice de peróxidos e índice de refração. Concluiu-se que as determinações de CPT, índice de acidez e índice de refração à temperatura de $40^{\circ} \mathrm{C}$ para óleos e $60^{\circ} \mathrm{C}$ para amostras com ponto de fusão mais alto são bons indicadores do nível de alteração do óleo. 
Além do aumento de ácidos graxos livres, os óleos apresentam aumento na viscosidade, no índice de refração, no escurecimento e na concentração de CPT quando comparados a óleos que não foram aquecidos. A presença de ácidos graxos poli-insaturados contribui para tornar o produto mais susceptível à ruptura das insaturações, demonstrando aumento do índice de refração ${ }^{12}$. O índice de refração à temperatura de $60^{\circ} \mathrm{C}$ detecta a qualidade dos óleos, sendo específico para cada tipo de fritura e dependente da temperatura utilizada e do tempo de fritura ${ }^{9}$. A avaliação à temperatura de $40^{\circ} \mathrm{C}$ não foi considerada um bom parâmetro para verificação da qualidade de óleo ${ }^{49}$.

Outro método para determinar produtos secundários da oxidação de lipídeos é o teste de p-anisidina, que detecta principalmente 2-alquenais, produtos secundários da oxidação de lipídeos. O número de anisidina é definido como 100 vezes a densidade óptica medida a $350 \mathrm{~nm}$ em uma cubeta de $1 \mathrm{~cm}$ de solução contendo $1 \mathrm{~g}$ de óleo em $100 \mathrm{~mL}$ de mistura de solvente e reagente. Os peróxidos presentes no óleo ou gordura oxidada, gordura de origem animal ou óleo de origem vegetal são intermediários transitórios que se decompõem em vários compostos carbonílicos e outros compostos, principalmente 2,4-dienais e 2-alquenais, na presença de p-anisidina em meio ácido ${ }^{55}$.

Para Sanibal \& Mancini Filho ${ }^{30}$, a acidez e o índice de peróxidos isolados não são medidas recomendadas para avaliação da deterioração de óleos e gorduras de fritura, mesmo assim são os únicos parâmetros químicos escolhidos pela norma brasileira para regulamentar a adequação de óleo para o consumo no país. Contudo, no Brasil, ainda não existe legislação específica para óleo ou gordura de fritura.

\section{REGULAMENTAÇÕES SOBRE FRITURA}

É difícil de ser estabelecida a linha tênue entre a economia do descarte do óleo/gordura no momento correto e a preservação da saúde do consumidor. Ainda não há no país nenhum regulamento sobre o assunto, apenas um informe técnico. A Resolução Diretiva Colegiada (RDC) $n^{\circ} 216^{56}$ define que a temperatura de óleo de fritura não deve ultrapassar $180^{\circ} \mathrm{C}$. A RDC $n^{\circ}$ $270^{57}$ regulamenta os padrões de identidade e as características mínimas de qualidade de óleos vegetais, gorduras vegetais e creme vegetal quanto à acidez e índice de peróxidos no geral, mas não em óleo ou gordura de fritura.

Em dezembro de 2003, no Brasil, a Agência Nacional de Vigilância Sanitária (Anvisa) recebeu documentação de uma Associação de Defesa do Consumidor (IDEC) requerendo participação nas ações para criação de Norma Brasileira que disponha sobre a utilização e o descarte de óleos e gorduras utilizados para fritura. Em resposta a essa solicitação, formulou-se o Informe Técnico $n^{\circ} 11$, de 5 de outubro de 2004, que estabelece que a quantidade de ácidos graxos livres não seja superior a 0,9\%; o teor de CPT não maior que $25,0 \%$ e que os valores de ácido linolênico, presente nas frituras, não ultrapassem o limite de $2,0 \%{ }^{58}$. O teor de ácido linolênico é crítico em frituras em razão da estabilidade do óleo e do aparecimento de flavor indesejável no alimento frito $^{28}$.

Vários países têm estabelecido regulamentos para o controle da qualidade dos óleos e gorduras utilizados para fritura, fixando limites máximos para os compostos polares (de 24 a $27 \%$ ), índice de peróxidos de $15 \mathrm{meq} / \mathrm{kg}$ e acidez (de 1,0\% a 2,5\%, expressa em ácido oleico) ${ }^{59}$. Em alguns países da Europa e nos Estados Unidos, seguem-se essas regulamentações para controle de qualidade de óleos de fritura, acrescentando ponto de fumaça entre $170-180^{\circ} \mathrm{C}^{60}$.

Na América do Sul, o Chile foi pioneiro na regulamentação em óleo de fritura, estabelecendo limites de 2,5\% para ácidos graxos livres (expressos em ácido oleico), 25,0\% para CPT e $170^{\circ} \mathrm{C}$ para ponto de fumaça9,61.

Nota-se que ainda não há um consenso entre os países, principalmente quanto aos limites de ácidos graxos livres, com uma variação entre $0,9 \%$ e $2,5 \%$. Muitos ainda não estabeleceram nenhuma regulamentação sobre óleo ou gordura de fritura. 


\section{EFEITO NA SAÚDE}

Durante o processo de fritura, são formados produtos tóxicos ou cancerígenos, tais como acroleína e peróxidos ${ }^{16}$. Além disso, as alterações físicas e químicas dos óleos de fritura podem levar à produção de aldeídos, cetonas, radicais livres e ácidos graxos trans que são incorporados aos alimentos fritos e também são prejudiciais à saúde humana. Tais compostos podem causar doenças de natureza cardiovascular, além de câncer, artrite e envelhecimento precoce ${ }^{62}$.

O câncer ou neoplasias malignas têm seu desenvolvimento influenciado direta ou indiretamente pela qualidade e tipo do alimento, assim como pelo emprego de métodos inadequados de preparo e de conservação dos produtos alimentícios ${ }^{16}$. Uma das associações mais estudadas em epidemiologia tem sido a gordura na dieta e o câncer de mama. O foco da prevenção é a modificação do estilo de vida63.

Os compostos formados pela oxidação de lipídeos possivelmente inibem ou pelo menos retardam a ação da lipase pancreática na hidrólise de triacilgliceróis não oxidados, tornando a digestibilidade bastante diminuída com o aumento dos compostos poliméricos ${ }^{12,64}$.

Estudos com óleos aquecidos por longos períodos, a temperaturas elevadas, demonstraram que os produtos resultantes contêm mais de 50\% de CPTs, e esses elevados teores provocaram severas irritações do trato gastrintestinal, diarreia, redução do crescimento e, em alguns casos, morte de animais (ratos) em laboratório ${ }^{16}$.

Diversos estudos comprovam a influência da alimentação nos lipídios séricos e na evolução da aterosclerose, e outros mostram a dificuldade de fazer a população melhorar seus hábitos alimentares ${ }^{65,66}$. O tipo de ácido graxo oferecido na dieta pode levar ao aumento de gordura no tecido adiposo, ganho de peso corporal e, consequentemente, o desenvolvimento de doenças crônicas não transmissíveis. Em geral, os ácidos graxos saturados tendem a elevar o colesterol sérico em todas as frações de lipoproteínas. Entretanto, o consumo de alimentos fontes de ácidos graxos poli-insaturados, principalmente ômega-3 e ômega-6, está associado a uma redução do risco de desenvolvimento de várias doenças, como aterosclerose e doenças cardiovasculares. Recentemente, os ácidos graxos trans também foram incluídos entre os fatores dietéticos de risco para as doenças cardiovasculares, sendo seu principal efeito metabólico a ação hipercolesterolêmica, que eleva o colesterol total e a lipoproteína de baixa densidade (Low Density Lipoprotein - LDL), o que reduz a lipoproteína de alta densidade (High Density Lipoprotein - HDL), resultando em significativo aumento na relação da LDL/HDL².

Sob condições de fritura, os óleos são levados à formação de inúmeros isômeros geométricos trans dos ácidos graxos oleico, linoleico e alfa-linolênico ${ }^{64}$. Os isômeros geométricos trans de ácidos graxos insaturados são formados no processo de fritura, assim como no refino de óleos e no processo de hidrogenação, por mecanismo induzido termicamente. Eles são identificados em vários tipos de alimentos, por exemplo, em margarinas vegetais, massas e recheios de biscoitos, nas formulações de bases para sopas e cremes, nos produtos de panificação, nas coberturas de bolos, entre outros. Pelas características estruturais, os ácidos graxos na forma trans têm seu ponto de fusão mais elevado quando comparado com seu isômero cis correspondente, e semelhante ao ponto de fusão do ácido graxo saturado com mesmo número de átomos de carbono. Sendo assim, os isômeros trans podem ser considerados como um intermediário entre um ácido graxo original insaturado cis e um ácido graxo completamente saturado. Os ácidos graxos trans de maior ocorrência são os monoinsaturados, mas vários isômeros di-insaturados ou mesmo tri-insaturados podem ser formados a partir dos ácidos linoleico e linolênico ${ }^{30,67}$.

Do ponto de vista nutricional, considera-se que os trans-isômeros são digeridos, absorvidos e incorporados pelo organismo de forma semelhante aos cis-isômeros. Entretanto, não apresentam atividade como ácidos graxos essenciais. 
O efeito dos trans-isômeros sobre a colesterolemia vem sendo motivo de vários estudos que têm indicado efeitos semelhantes desses ácidos aos de ácidos graxos saturados. Existem, ainda, aspectos não totalmente elucidados quanto à influência dessas substâncias na gênese de doenças ateroscleróticas, alguns tipos de câncer e outros problemas ligados à saúde ${ }^{68}$.

Há evidências de que ratos Wistar, alimentados com óleos ou gorduras exaustivamente processados em fritura, na concentração de $10 \%$ na dieta, durante 35 dias, podem apresentar alterações metabólicas que resultam na perda de peso, supressão do crescimento, diminuição do tamanho do fígado e dos rins, má absorção de gordura, diminuiçã̃o da taxa de dessaturação dos ácidos graxos linoleico e alfalinolênico, além do aumento da taxa de colesterol no fígado e fertilidade reduzida ${ }^{2}$.

Os compostos formados pela decomposição de ácidos graxos insaturados durante o processo de fritura afetam a disponibilidade dos ácidos graxos essenciais, linoleico e alfa-linolênico, responsáveis pela biossíntese dos ácidos araquidônico, eicosapentaenoico e docosahexaenoico, na formação das prostaglandinas, tromboxanos e prostaciclinas, compostos que participam da regulação da pressão arterial, frequência cardíaca, resposta imunológica, dos processos da coagulação sanguínea e do funcionamento do sistema nervoso central ${ }^{30}$. Assim, além dos efeitos maléficos dos compostos da degradação do óleo, tem-se também a diminuição dos efeitos benéficos à saúde de ácidos graxos essenciais presentes em alguns óleos e a destruição de vitaminas lipossolúveis devido à autooxidação dos triacilgliceróis de ácidos graxos insaturados²,12,58.

\section{RECOMENDAÇÕES PARA A MELHORIA DA QUALIDADE DO ÓLEO/GORDURA DE FRITURA E SEUS DESCARTES}

As recomendações específicas do Parlamento Europeu ${ }^{59}$ focalizaram a reciclagem do óleo, além de recomendações especificadas co- mo: estabelecer controles nas empresas envolvidas, promover a utilização de testes rápidos de análises para restaurantes, melhorar a qualidade do óleo, promover a utilização da fritura contínua, melhorar os sistemas de fritura descontínua e planejar equipamentos com menor capacidade para reduzir o desperdício de óleo ${ }^{1}$.

Além das recomendações de valores máximos de acidez e CPT, o Informe Técnico n 11, no Brasil ${ }^{58}$, apresenta também as seguintes recomendações de boas práticas para utilização e descarte de óleo ou gordura de fritura:

"1. A temperatura máxima para fritura deve ser de $180^{\circ} \mathrm{C}$. Esta deve ser controlada através de termostato já presente nas fritadeiras industriais. No caso das fritadeiras de uso doméstico (frigideiras, panelas e tachos) que não possuam termostato para controle, não se deve permitir a elevação da temperatura a ponto de produzir fumaça. Temperaturas excessivamente altas degradam o óleo rapidamente e provocam a emissão de fumaça.

2. Dar preferência pela fritura contínua, ao invés de utilizar fritadeira/frigideira/ tacho por vários períodos curtos, ou seja, em aquecimento intermitente e descontínuo.

3. Caso a fritadeira/frigideira/tacho não esteja sendo utilizada, mas existe a necessidade de mantê-la ligada para um uso iminente, a mesma deve estar parcialmente tampada, assim se evita o contato do óleo quente com o oxigênio do ar, pois o óleo muito quente absorve o oxigênio do ar em maior quantidade promovendo sua oxidação.

4. Evitar completar o óleo em uso presente na fritadeira/frigideira/tacho com óleo novo. É preferível descartar a sobra de um óleo já utilizado.

5. Em intervalos de uso, o óleo deve ser armazenado em recipientes tampados e protegidos da luz, para evitar o contato 
com os principais catalisadores de oxidação, oxigênio e luz. Se o intervalo entre os usos for longo, além de tampado, o óleo deve ser armazenado sob refrigeração, para se aumentar a vida de prateleira.

6. O óleo deve ser filtrado a cada término de uso. Durante a fritura dos alimentos, especialmente dos empanados, as partículas liberadas devem ser removidas.

7. O óleo deve ser descartado quando se observar formação de espuma e fumaça durante a fritura, escurecimento intenso do óleo e do alimento e percepção de odor e sabor não característicos. Cabe lembrar que o aspecto da fumaça é diferente do vapor naturalmente liberado.

8. As fritadeiras/frigideiras/tachos devem possuir os cantos arredondados, ou seja, não apresentar cantos que propiciem o acúmulo de resíduos, pois o óleo polimerizado e depositado nas paredes tende a catalisar reações de degradação do óleo.

9. As fritadeiras/frigideiras/tachos devem ser de material resistente e quimicamente inerte, ou seja, que não contamine os alimentos ou facilite a oxidação do óleo com a presença de cobre ou ferro. Devem ser descartados quando considerados danificados (riscados, amassados, descascados).

10. O óleo não deve ser descartado na rede pública de esgoto. As donas de casa podem acondicioná-lo em sacos plásticos ou recipientes e juntá-lo ao lixo orgânico. Já para os comerciantes e lojas do tipo fast food, por descartarem uma quantidade significativa, sugere-se entrar em contato com empresas, órgãos ou entidades licenciados pelo órgão competente da área ambiental" (p.1-2).

Outros autores acrescentam mais recomendações: é importante certificar-se de que não haja detergente ou materiais de limpeza no recipiente no qual o óleo será aquecido. No momento em que qualquer alteração for detectada no óleo utilizado para fritura por imersão, o produto deverá ser descartado ${ }^{14}$.

\section{O N C L US Ã O}

É de suma importância dispor de métodos analíticos rápidos e simples que permitam conhecer a qualidade dos óleos de fritura dentro dos padrões da legislação e uma melhor informação das indústrias e dos estabelecimentos comerciais desse setor. A utilização de testes colorimétricos e por constante dielétrica, como indicativo do ponto de descarte do óleo ou gordura, sugere ser uma estratégia rápida, barata e possível de ser realizada no dia a dia das indústrias de alimentos e de unidades produtoras de refeições. Aliado a isso, a identificação de alteração da aparência, da cor, da textura do meio de fritura também se faz importante.

É necessária a realização de novos estudos com intuito de contribuir com os órgãos de fiscalização de qualidade de alimentos para estabelecer os parâmetros físicos e químicos para o descarte do óleo e/ou gordura de fritura, nas situações em que são utilizados pelos manipuladores de alimentos no Brasil, bem como diagnosticar o atual perfil de utilização e de descarte desses produtos no país.

Ressalta-se ainda que, do ponto de vista do consumidor, a qualidade nutricional, o sabor e a aparência dos alimentos devem também ser considerados. Do ponto de vista do comerciante, torna-se um grande desafio oferecer um alimento de boa qualidade aliado à eficiência e ao custo do processo de fritura.

\section{REFERÊ NCIAS}

1. Almeida DT, Araújo MPN, Furtunato DMN, Souza JC, Moraes TM. Revisão de literatura: aspectos gerais do processo de fritura de imersão. Hig Alimentar. 2006; 20(138):42-7.

2. Corsini MS, Jorge N, Miguel AMRO, Vicente E. Perfil de ácidos graxos e avaliação da alteração em óleos 
de fritura. Quím Nova. 2008; 31(5):956-61. doi: 10.1590/S0100-40422008000500003.

3. Jorge N, Lopes MRV. Avaliação de óleos e gorduras de frituras coletados no comércio de São José do Rio Preto - SP. Aliment Nutr. 2003; 14(2):149-56.

4. Ruschel CK, Carvalho HH, Souza RB, Tondo EC. Qualidade microbiológica e físico-química de suco de laranja comercializados nas vias públicas de Porto Alegre - RS. Ciênc Tecnol Aliment. 2001; 21(1):94-7. doi: 10.1590/S0101-20612001000100020.

5. Instituto Brasileiro de Geografia e Estatística. Pesquisa de orçamentos familiares 2002-2003: aquisição domiciliar per capita, Brasil e grandes regiões. Rio de Janeiro: IBGE; 2004.

6. Instituto Brasileiro de Geografia e Estatística. Pesquisa de Orçamentos Familiares 2008-2009: despesas, rendimentos e condições de vida. Rio de Janeiro: IBGE; 2010.

7. Fritsch $C W$. Measurements of frying fat deterioration: A brief review. JAOCS. 1981; 58(3):272-4. doi: 10.1007/BF02582355.

8. Marques ACV, Tessa B, Rosa CS. Formação de toxinas durante o processamento de alimentos e as possíveis conseqüências para o organismo humano. Rev Nutr. 2009; 22(2):283-93. doi: 10.1590/\$1415-52 732009000200010.

9. Malacrida $C R$, Jorge N. Alterações do óleo de soja em frituras: efeitos da relação superfície/volume e do tempo de fritura. Hig Alimentar. 2005; 19(129): 25-31.

10. Aladedunye FA, Przybylski R. Degradation and nutritional quality changes of oil during frying. JAOCS. 2009; 86(2):149-56. doi: 10.1007/s11746-00 8-1328-5.

11. Borgo LA, Araújo WMC. Mechanisms of the process of lipid oxidation. Hig Alimentar. 2005; 19(30):50-8.

12. Gregório BM, Andrade ECB. Influência do aquecimento sobre as propriedades físico-químicas de óleos comestíveis. Hig Alimentar. 2004; 18(124): 78-84.

13. Ramalho $V$, Jorge N. Antioxidantes utilizados em óleos, gorduras e alimentos gordurosos. Quím Nova. 2006; 29(4):755-60. doi: 10.1590/S0100-4042 2006000400023.

14. Fox NJ, Stachowiak GW. Vegetable oil-based lubricants: A review of oxidation. Tribol Int. 2007; 40(7):1035-046. doi: 10.1016/j.triboint.2006.10.0 01.

15. Machado ER, Marmesat S, Abrantes S, Dobarganes C. Uncontrolled variables in frying studies: Differences in repeatability between thermoxidation and frying experiments. Grasas Aceites. 2007; 58(3):283-8.
16. Marques AC, Valente TB, Rosa CS. Formação de toxinas durante o processamento de alimentos e as possíveis conseqüências para o organismo humano. Rev Nutr. 2009; 22(2):283-93. doi: http:// dx.doi.org/10.1590/S1415-52732009000200010.

17. Kita G, Lisinska G, Golubowska G. The effects of oils and frying temperatures on the texture and fat content of potato crisps. Food Chem. 2007; 102(1): 1-5. doi: 10.3923/ajft.2011.753.762.

18. Ziaiifar AM, Achir N, Courtois F, Trezzani I, Trystram $\mathrm{G}$. Review of mechanisms, conditions, and factors involved in the oil uptake phenomenon during the deep-fat frying process. Int J Food Sci Technol. 2008; 43(8):1410-23. doi: 10.1111/j.1365-262 1.2007.01664.x.

19. Cella RCF, Regitano-D'arce MAB, Spoto MHF. Comportamento do óleo de soja refinado utilizado em fritura por imersão com alimentos de origem vegetal. Ciênc Tecnol Aliment. 2002; 22(2):111-6. doi: 10.1590/S0101-20612002000200002.

20. Del Ré PV, Coltro AL, Manente JCPP, Marti GE, Jorge N. Influência da relação superfície/volume em frituras de batata palito. Rev Inst Adolfo Lutz. 2003; 62(3):213-9.

21. McSavage J, Trevisan S. The use and abuse of frying oil. Food Service Technol. 2001; 1(2):85-92. doi: 0.10 46/j.1471-5740.2001.00013.x.

22. Mendonça MA, Borgo LA, Araújo WMC, Novaes MRCG. Alterações físico-químicas em óleos de soja submetidos ao processo de fritura em unidades de produção de refeição no Distrito Federal. Comun Ciênc Saúde. 2008; 19(2):115-22.

23. Juárez MD, Osawa CC, Acunã ME, Sammán N, Gonçalves LAG. Degradation in soybean oil, sunflower oil and partially hydrogenated fats after food frying, monitored by conventional and unconventional methods. Food Control. 2011; 22(12):1920-7. doi: 10.1016/j.bbr.2011.03.031.

24. Corsini MS, Jorge N. Estabilidade oxidativa de óleos vegetais utilizados em frituras de mandioca palito congelada. Ciênc Tecnol Aliment. 2006; 26(1):27-32. doi: 10.1590/S0101-20612006000100005.

25. Damy PC, Jorge N. Determinações físico-químicas do óleo de soja e da gordura vegetal hidrogenada durante o processo de fritura descontínua. Braz J Food Technol. 2003; 6(2):251-7.

26. Choe E, Min DB. Chemistry of deep-fat frying oils. J Food Sci. 2007; 72(5):R77-R86. doi: 10.1111/j.17 50-3841.2007.00352.x.

27. Uriarte PS, Guillén MD. Formation of toxic alkylbenzenes in edible oils submitted to frying temperatura influence of oil composition in main components and heating time. Food Res Inter. 2010; 43(8):2161-70. doi: 10.1016/j.orgel.2007.0 6.002 . 
28. Araújo JMA. Química de alimentos: teoria e prática. $4^{a}$ ed. Viçosa: Editora UFV; 2008.

29. Souza AHP, Felicidade LD, Bowles S. Comportamento da gordura vegetal hidrogenada utilizada em restaurante na cidade de Londrina-PR. In: Anais do XIV Seminário de Iniciação Científica e Tecnológica da UTFPR; 2009 nov 11-13; Pato Branco: UTFPR; 2009. Seção Alimentos, v.1.

30. Sanibal EAA, Mancini Filho J. Alterações física, químicas e nutricionais de óleos submetidos ao processo de fritura. Food Ingr South Am. 2002; 1(3): 64-71.

31. Associação Brasileira das Indústrias da Alimentação. Compêndio da legislação de alimentos. $7^{\text {a }}$ ed. São Paulo: ABIA; 1999.

32. Reda SY. Avaliação da estabilidade de antioxidantes por análise térmica e seu efeito protetor em óleo vegetal aquecido. Ciênc Tecnol Aliment. 2011; 31(2):475-80. doi: 10.1590/S0101-206120110002 00030.

33. Ramalho VC, Jorge N. Antioxidants used in oils, fats and fatty foods. Quím Nova. 2006; 29(4): 755-60. doi: 10.1590/S0100-404220060004000 23.

34. Roos YH. Thermal analysis, state transitions and food quality. J Therm Anal Calorim. 2003; 71(1):197-203. doi: 10.1023/A:1022234805054.

35. Yilmaz MT, Karakaya M. Differential scanning calorimetry analysis of goat fats: Comparison of chemical composition and thermal properties. J Am Oil Chem Soc. 2009; 86(90):877-83. doi: 10.1007/ s11746-009-1420-5.

36. Kim Jl, Lee JH, Choi DS, Won B, Jung MY, Park JY. Kinetic study of the quenching reaction of singlet oxygen by common synthetic antioxidants (tertButylhydroxyanisol, tert-di-Butylhydroxytoluene, and tert-Butylhydroquinone) as compared with $\alpha$-tocopherol. J Food Sci. 2009; 74(5):363-9. doi: 10.1111/j.1750-3841.2009.01160.x.

37. Stier RF. Tests to monitor quality of deep-frying fats and oils. Eur J Lipid Sci Technol. 2004; 106(2004): 766-71. doi: 10.1002/ejlt.200401049.

38. Marmesat S, Machado ER, Velasco J, Dobarganes C. Quality of used frying fats and oils: Comparison of rapid tests based on chemical and physical oil properties. Inter J Food Sci Tech. 2007; 42(5):601-8. doi: 10.1111/j.1365-2621.2006.01284.x.

39. Cunha SS, Fernandes JO, Oliveira MBPP. Quantification of free and esterified sterols in Portuguese olive oils by solid-phase extraction and gas chromatography-mass spectrometry. J Chromatogr A. 2006; 1128(1-2):220-7.

40. Mariano C, Bellan G, Lestini E, Aparicio R. The detection of the presence of hazelnut oil in olive oil by free and esterified sterols. Eur Food Res
Technol. 2006; 223(5):655-61. doi: 10.1007/s00 217-005-0249-x.

41. Bertanha BJ, Santos AB, Luiza DMM, Jorge N. Avaliação da qualidade de óleos e gorduras de fritura por meio de testes rápidos. Hig Alimentar. 2009; 23(172-173):177-82.

42. Osawa CC, Gonçalves LAG, Grimaldi R. Emprego do fri-check na avaliação da qualidade de óleos e gorduras de fritura. Hig Alimentar. 2006; 20(145): 73-9.

43. Rywotycki R. Food frying process control system. J Food Eng. 2003; 59(4):339-42. doi: 10.1016/S02 60-8774(02)00491-0.

44. Marcone ALO, Claudimir LL, Marina FMT. Análise de ácidos graxos por eletroforese capilar utilizando detecção condutométrica sem contato. Quím Nova. 2003; 26(6):821-4. doi: 10.1590/S0100-404220 03000600007.

45. Silva JAF. Detecção eletroquímica em eletroforese capilar. Quím Nova. 2003; 26(1):56-64. doi: 10.15 90/S0100-40422003000100012.

46. Emmanuel H, George D, Alexia A, Photis D. A facile NMR method for the quantification of total, free and esterified sterols in virgin olive oil. Food Chem. 2010; 122:346-52. doi: 10.1016/j.foodchem.20 10.02.043.

47. Guillén MD, Uriarte PS. Study by $1 \mathrm{H} N \mathrm{NMR}$ spectroscopy of the evolution of extra virgin olive oil composition submitted to frying temperature in an industrial fryer for a prolonged period of time. Food Chem. 2012; 134(1):162-72. doi: 10.1016/j. foodchem.2012.02.083.

48. Mattos ES, Ans VG, Jorge N. Utilização do kit oil test para avaliação da alteração dos óleos de fritura. Hig Alimentar. 2000; 14(75):40-7.

49. Tavares M, Gonzalez E, Silva MLP, Barsotti RCF, Kumagai EE, Caruso MSF, et al. Avaliação da qualidade de óleos e gorduras utilizados para fritura no comércio da Região Metropolitana da Baixada Santista, estado de São Paulo. Rev Inst Adolfo Lutz. 2007; 66(1):40-4.

50. Lopes MRV, Jorge N. Testes rápidos utilizados na avaliação da qualidade de óleos e gorduras de fritura. Rev Inst Adolfo Lutz. 2004; 63(1):73-9.

51. Waltking AE, Wessels $H$. Chromatographic separation of polar and non-polar components of frying fats. JAOAC. 1981; 64(6):1329-30.

52. Instituto Adolfo Lutz. Óleos e gorduras. In: Zenebon O, Pascuet NS, Tiglea P., coordenadores. Métodos físico-químicos para análise de alimentos. São Paulo: Instituto Adolfo Lutz; 2008.

53. Jorge N, Lunardi VM. Comportamento de óleos poliinsaturados em frituras descontínuas de batatas. Aliment Nutr. 2004; 15(2):119-24. 
54. Jorge N, Janieri C. Avaliação do óleo de soja submetido ao processo de fritura de alimentos diversos. Ciênc Agrotec. 2005; 29(5):1001-7. doi: 10.1590/S1 413-70542005000500013.

55. American Oil Chemists' Society. Official methods and recommended practices of the American Oil Chemists' Society. Champaign: American Oil Chemists' Society; 2004.

56. Brasil. Ministério da Saúde. Agência Nacional de Vigilância Sanitária. Resolução RDC n²16, de 15 de setembro de 2004. Dispõe sobre regulamento técnico de boas práticas para serviços de alimentação. Brasília: Anvisa; 2004 [acesso 2010 abr 23]. Disponível em: <http://www.anvisa.gov.br/ alimento/informes>.

57. Brasil. Ministério da Saúde. Agência Nacional de Vigilância Sanitária. Resolução RDC n²70, de 22 de setembro de 2005. Aprova o regulamento técnico para óleos vegetais, gorduras vegetais e creme vegetal. Brasília: Anvisa; 2005 [acesso 2010 maio 9]. Disponível em: <http://www.anvisa.gov.br/ alimento/informes>.

58. Brasil. Ministério da Saúde. Agência Nacional de Vigilância Sanitária. Informe Técnico $n^{\circ} 11$, de 5 de outubro de 2004. Dispõe sobre boas práticas de fabricação para utilização e descarte de óleos utilizados em frituras. Brasília: Anvisa, 2004 [acesso 2010 abr 23]. Disponível em: <http://www.anvisa. gov.br/alimento/informes>.

59. Codex Alimentarius. Codex standard for olive oils and olive pomace oils. Roma: Food and Agriculture Organization; 2001.

60. Firestone D, Stier RF, Blumenthal MM. Regulation of frying fats and oils. Food Technol. 1991; 45(2): 90-4.

61. Chile. Ministerio de Salud. Regulamento sanitário de los alimentos, $n^{\circ} 75$ D.O. 13. 01. 2000. No deberán utilizarse los aceites o mantecas cuando sobrepasen los limites. Santiago: Seremi Region Metropolitana; [s.d.]. [accesso 2011 mar 22]. Disponible en: <http//: seremisaludrm.cl/sitio/dowload/normativaseremi/ DecretoN977RegulamentmodelosAlimentos.pdf>.

62. Rique $A B R$, Soares EA, Meirelles CM. Nutrição e exercício na prevenção e controle das doenças cardiovasculares. Rev Bras Med Esporte. 2002; 8(6): 244-54. doi: 10.1590/\$1517-869220020006000 06.

63. Lee MM, Lin SS. Dietary fat and breast cancer. Ann Rev Nutr. 2000; 20:221-48. doi: 10.3945/ajcn.11 1.015735 .

64. Carvalho SM, Ogliari PJ, Barrera-Arellano D, Block JM. Efeito da adição de tocoferóis naturais sobre a qualidade de óleo de soja refinado e embalado em PET durante a estocagem. Braz J Food Technol. 2008; 11(2):134-43.

65. Scherr C, Ribeiro JP. Colesterol e gorduras em alimentos brasileiros: implicações para a prevenção da aterosclerose. Arq Bras Cardiol. 2009; 92(3):1905. doi: 10.1590/S0066-782X2009000300005.

66. Dansinger ML, Gleason JA, Griffithjl SHP, Schaefer EJ. Comparison of the Atkins, Ornish, Weight Watchers, and Zone diets for weight loss and heart disease risk reduction: A randomized trial. Jama. 2005; 293(1):43-53. doi: 10.1001/jama.293.1.43.

67. Valenzuela A, Morgado N. Trans fatty acid isomers in human health and in the food industry. Biol Rev. 1999; 32(4):273-87. doi: 10.4067/S0716-976019 99000400007.

68. Mancini- Filho J. Avaliação da participação dos ácidos graxos trans em processos metabólicos. In: Ciências dos alimentos: avanços e perspectivas na América Latina. São Paulo: Instituto Adolfo Lutz; 1997. v.63-64.
Recebido em: 5/7/2012

Versão final em: 11/10/2012

Aprovado em: 13/11/2012 